\title{
Magnetically-modified natural biogenic iron oxides for organic xenobiotics removal
}

\author{
I. Safarik · J. Filip $\cdot$ K. Horska $\cdot$ M. Nowakova $\cdot$ \\ J. Tucek $\cdot$ M. Safarikova $\cdot$ H. Hashimoto $\cdot$ \\ J. Takada $\cdot$ R. Zboril
}

Received: 10 May 2012/Revised: 12 October 2013/Accepted: 24 November 2013/Published online: 17 December 2013

(C) Islamic Azad University (IAU) 2013

\begin{abstract}
Biogenic iron oxides have been collected from a water stream and subsequently magnetically modified using water-based magnetic fluid. Both natural and magnetically modified materials have been characterized in detail using wavelength dispersive X-ray fluorescence spectrometry, X-ray powder diffraction, Mössbauer spectroscopy, electron microscopy and BET surface area measurements. The natural material is composed of 2-line ferrihydrite, forming hollow microtubules-sheaths of Leptothrix ochracea, and detrital components. As a result of the ferrofluid modification, maghemite nanoparticles were identified on the surface of the treated material. The active surface area of the bulk, magnetically-modified sample was $148 \mathrm{~m}^{2} \mathrm{~g}^{-1}$. The magnetically modified material was tested as inexpensive magnetically responsive adsorbent for the removal of selected organic xenobiotics,
\end{abstract}

Electronic supplementary material The online version of this article (doi:10.1007/s13762-013-0455-1) contains supplementary material, which is available to authorized users.

I. Safarik $(\bowtie) \cdot$ K. Horska $\cdot$ M. Safarikova

Department of Nanobiotechnology, Institute of Nanobiology and Structural Biology of GCRC, Academy of Sciences, Na Sadkach

7, 37005 Ceske Budejovice, Czech Republic

e-mail: ivosaf@yahoo.com

URL: http://www.nh.cas.cz/people/safarik

I. Safarik · J. Filip · M. Nowakova · J. Tucek · R. Zboril Departments of Experimental Physics and Physical Chemistry, Regional Centre of Advanced Technologies and Materials, Palacky University, 17. listopadu 1192/12, 77146 Olomouc, Czech Republic

H. Hashimoto $\cdot$ J. Takada

Department of Applied Chemistry, Graduate School of Natural

Science and Technology, Okayama University,

Okayama 700-8530, Japan namely organic dyes, from aqueous solutions. The observed maximum adsorption capacities ranged between 34.3 and $97.8 \mathrm{mg}$ of dye per $1 \mathrm{~g}$ of adsorbent.

Keywords Biogenic iron oxides - Leptothrix ochracea . Magnetic fluid - Magnetic adsorbents - Xenobiotics

\section{Introduction}

Different types of (micro)organisms are able to produce mineral nanoparticles by the process of biomineralization, using one of two existing basic strategies, namely biologically controlled mineralization and biologically induced mineralization (Bazylinski et al. 2007). In water streams, generally characterized by moderate to high concentration of dissolved $\mathrm{Fe}^{2+}$ ions, low partial pressure of oxygen and circumneutral or acidic $\mathrm{pH}$, usually red/orange layers of iron oxides/hydroxides are formed by iron-oxidizing bacteria (Ghiorse 1984; Emerson et al. 2010). Several morphologically distinct species, such as Gallionella ferruginea (twisted stalks) and Leptothrix ochracea (elongated tubes) are well known and, in fact, most widespread producers of biogenic iron oxides in diverse aquatic environments (James and Ferris 2004). These bacteria are also recognized in engineered systems, where they contribute to clogging of wells, pipes and draining-systems; iron oxidizing bacteria have also been exploited by the water treatment industry for efficient and cheap $\mathrm{Fe}^{2+}$-ions removal (Rentz et al. 2009).

Iron-rich and iron-oxide containing materials have been widely used as adsorbents namely for both phosphorus (Mayer and Jarrell 2000; Kang et al. 2003; Chitrakar et al. 2006) and arsenic (Jeong et al. 2007; Hartley and Lepp 2008; Sabbatini et al. 2009) removal. In addition to 
synthetic iron-containing materials, biogenic iron oxides, produced e.g., by G. ferruginea and L. ochracea have been successfully used for removal of the above mentioned species (Katsoyiannis and Zouboulis 2004; Pokhrel and Viraraghavan 2009; Rentz et al. 2009).

Magnetic separation is a promising technique for easy removal of magnetic or magnetically-modified sorbents containing adsorbed biologically active compounds or xenobiotics from difficult-to-handle environments (Safarikova and Safarik 2001). Magnetic nano- and micro-particles have already been applied in various areas of biosciences, biotechnologies, (bio)analytical chemistry and environmental technologies directly as adsorbents enabling their magnetic separation; alternatively they have been successfully used for magnetic modification of originally non-magnetic sorbents to form magnetically responsive composites (Safarikova and Safarik 2001; Safarik and Safarikova 2002b, 2010a). In environmental technology and chemistry, such materials have been successfully used both in small (i.e., laboratory) scale (Safarik and Safarikova 2010a) and industrial-scale processes. The large-scale process "Sirofloc", based on finely ground magnetite, is employed in several water treatment systems in Australia, Asia and Europe (Bolto 1996). Moreover, magnetic particles are helpful for pre-concentration of target xenobiotics such as malachite green and crystal violet from large volumes of liquids using the process of magnetic solid-phase extraction (Safarik and Safarikova 2002a). Accordingly, magnetically-modified yeast cells and plant-derived materials were tested for removal of organic dyes and mercury ions (Safarik and Safarikova 2010a).

New inexpensive magnetically responsive materials have to be developed in order to improve the potential of magnetic separation techniques. Most commercially available magnetic particles are rather expensive and cannot be used for large-scale processes. Magnetic modification of inexpensive adsorbents and carriers can lead to materials suitable for large-scale biotechnologies and environmental applications (Safarik and Safarikova 2009, 2010a). That is why in this study we have prepared magnetically-modified natural biogenic iron oxides as a possible inexpensive adsorbent and tested it for the removal of hazardous organic dyes from water solutions. The prepared adsorbent was characterized in detail utilizing state-of-theart multi-analytical approach.

\section{Materials and methods}

\section{Materials}

The natural ocherous sediment containing biogenic iron oxides was collected using glass vessels from an unnamed forest stream in Ceske Budejovice, Czech Republic $\left(48^{\circ} 58^{\prime} 26.069^{\prime \prime} \mathrm{N}, 14^{\circ} 27^{\prime} 58.753^{\prime \prime} \mathrm{E}\right)$ during end of February and beginning of March, 2010. Sample was concentrated during collection by letting the biogenic iron oxides settle down and decanting overlying water. Subsequently, the sediment was promptly transported to the laboratory, where it was at first sieved through a $1 \mathrm{~mm}$ sieve to remove larger detrital fraction, then repeatedly washed with deionized water and air dried at a temperature not exceeding $50{ }^{\circ} \mathrm{C}$. To disintegrate large aggregates, the sample was gently grinded in an agate mortar in order to keep mechanical treatment at minimum.

Bismarck brown Y (C.I. Basic Brown 1; C.I. 21000) and safranin O (C.I. Basic Red 2; C.I. 50240; a mixture of dimethyl safranin and trimethyl safranin) were provided by Sigma, USA. Crystal violet (C.I. Basic Violet 3; C.I. 42555) and methyl green (C.I. Basic Blue 20; C.I. 42585) were purchased from Loba Chemie, Austria. Malachite green (Basic Green 4; CI 42000) was obtained from Roth, Germany. Acridine orange (C.I. Basic Orange 14; C.I. 46005) was obtained from Merck, Germany while Nile blue A (C.I. Basic Blue 12; C.I. 51180) was from Chemische Fabrik, Germany. Chemical structures of the dyes are shown in Electronic Supplementary Material, Table S1. Water-based ionic magnetic fluid stabilized with perchloric acid was prepared using a standard procedure (Massart 1981). The ferrofluid was composed of maghemite nanoparticles with diameter ranging approximately between 10 and $15 \mathrm{~nm}$. The relative magnetic fluid concentration $\left(25.2 \mathrm{mg} \mathrm{mL}^{-1}\right)$ is given as the maghemite content determined by a colorimetric method (Kiwada et al. 1986). All chemicals were used without any further purification. All experiments were prepared with deionized water (Millipore).

Magnetic modification of biogenic iron oxides

$2 \mathrm{~g}$ of air-dried natural sample was suspended in $40 \mathrm{~mL}$ of methanol and $4 \mathrm{~mL}$ of perchloric-acid stabilized ferrofluid were added. The suspension was mixed on a rotary mixer (Dynal, Norway) for $1 \mathrm{~h}$ and then the magnetically modified material was washed two times with methanol and subsequently air-dried at room temperature. Then dried sample was powdered by gently grinding in an agate mortar in order to keep mechanical treatment at minimum.

Instrumentation employed for characterization of biogenic iron oxides

Total contents of major and trace elements in natural sample was determined by wavelength dispersive X-ray fluorescence spectrometry (WDXRF) using the S4 Pioneer (Bruker AXS) spectrometer. A pre-calibrated "standard- 
less" routine method of SpectraPlus and GeoQuant package (Bruker AXS), based on international rock standards and internal standards were used for quantitative chemical analysis of sample prepared into a form of pressed pellet. Loss on ignition (LOI) was determined conventionally based on drying (at $105{ }^{\circ} \mathrm{C}$ overnight) and subsequent combustion (at $1,070{ }^{\circ} \mathrm{C}$ for $1 \mathrm{~h}$ ) of the sample using laboratory muffle furnace.

X-ray powder diffraction (XRD) pattern of magnetically-modified sample was recorded on PANalytical X'Pert PRO (The Netherlands) instrument in Bragg-Brentano geometry with Fe-filtered $\mathrm{Co} K_{\alpha}$ radiation $(40 \mathrm{kV}, 30 \mathrm{~mA})$. The sample was inserted into conventional back-loading cavity sample holder and scanned in the $2 \theta$ range of $5^{\circ}-90^{\circ}$ in steps of $0.017^{\circ}$. The commercial standards SRM640 (Si) and SRM660 $\left(\mathrm{LaB}_{6}\right)$ from NIST were used for evaluation of the line positions and instrumental line broadening, respectively. The acquired pattern was evaluated using the $\mathrm{X}^{\prime}$ Pert HighScore Plus software (PANalytical), PDF-4+ and ICSD databases.

Both room- and low-temperature $(5 \mathrm{~K})$ transmission ${ }^{57} \mathrm{Fe}$ Mössbauer spectra of unmodified and magnetically modified samples were collected in a constant acceleration mode with a ${ }^{57} \mathrm{Co}(\mathrm{Rh})$ source. Prior to analysis, Mössbauer data were folded to produce a flat non-resonant background. A pure $\alpha$-Fe foil was used as a calibration standard. Spectra were fitted by the Lorentz functions using the computer program CONFIT2000 (Zak and Jiraskova 2006).

The morphological study of magnetically-modified sample was done on a field emission scanning electron microscope (SEM) Hitachi SU6600 with point-to-point resolution 1-2 $\mathrm{nm}$ and equipped with energy-dispersive $\mathrm{X}$-ray (EDX) spectrometer. Detailed morphological characterization was done by combination of JEM-2010 (JEOL) transmission electron microscope (TEM) equipped by $\mathrm{LaB}_{6}$ cathode (accelerating voltage of $200 \mathrm{kV}$; point-topoint resolution of $0.194 \mathrm{~nm}$ ) and TEM microscope JEM2100F (JEOL) equipped by CEOS Cs corrector for a STEM mode. A drop of high-purity distilled water, containing the ultrasonically dispersed biogenic iron oxides, was placed onto a holey-carbon film supported by a copper-mesh TEM grid and air-dried at room temperature. Selected area electron diffraction (SAED) was also employed.

A superconducting quantum interference device (SQUID, MPMS XL-7, Quantum Design) was used for the magnetic measurements. The hysteresis loops were collected at temperatures of 2 and $300 \mathrm{~K}$ and in external magnetic fields ranging from -7 to $+7 \mathrm{~T}$.

The specific surface area of the samples was determined from a BET3 method (non-linear, 3 parameters, full equation) in the $p / p_{0}$ range between 0 and 0.5 using a BET surface area analyzer, Coulter SA 3100 with $\mathrm{N}_{2}$ as an adsorption gas. The samples were de-gassed at room temperature with a pressure of $10^{-6} \mathrm{~Pa}$ for $12 \mathrm{~h}$.

Adsorption of dyes on magnetically-modified biogenic iron oxides

$30 \mathrm{mg}$ of magnetically-modified sample was mixed with $6.0 \mathrm{~mL}$ of water in a test tube. Then $0.1-4 \mathrm{ml}$ portion of stock water solution of a tested dye $\left(1 \mathrm{mg} \mathrm{mL}^{-1}\right)$ was added and the total volume of the solution was filled up to $10.0 \mathrm{~mL}$ with water. The suspension was mixed on a rotary mixer (Dynal, Norway) for $3 \mathrm{~h}$ at room temperature. Then the magnetic adsorbent was separated from the suspension using a magnetic separator (MPC-1 or MPC-6, Dynal, Norway) and the clear supernatant was used for the spectrophotometric measurement. The concentration of free (unbound) dye in the supernatant $\left(C_{\mathrm{eq}}\right)$ was determined from the calibration curve (see additional information in Electronic Supplementary Material, Fig. S1).

The amount of dye bound to the unit mass of the adsorbent $\left(q_{\mathrm{eq}}\right)$ was calculated using the following formula:

$q_{\mathrm{eq}}=\left(C_{t o t}-C_{\mathrm{eq}}\right) / 3 \quad m g g^{-1}$

where $\mathrm{C}_{\text {tot }}$ is the total concentration of dye $\left(\mu \mathrm{g} \mathrm{mL}^{-1}\right)$ used in the experiment. The value $q_{\mathrm{eq}}$ was expressed in $\mathrm{mg}$ of adsorbed dye per $1 \mathrm{~g}$ of adsorbent. Equilibrium adsorption data were fit to Langmuir and Freundlich adsorption isotherms using SigmaPlot software.

\section{Results and discussion}

Biogenic iron oxides

In this section we provide a detailed description of morphological, compositional, structural and magnetic characteristics of biogenic iron oxides from natural sediment intended for the sorption removal of organic xenobiotics.

The studied biogenic iron oxides were produced by fast extracellular oxidation of soluble $\mathrm{Fe}^{2+}$ into less soluble $\mathrm{Fe}^{3+}$ precipitating rapidly in the form of poorly-crystalline iron oxides directly on the cells of L. ochracea (Hashimoto et al. 2007). They form characteristic hollow microtubules representing sheaths of L. ochracea. SEM and TEM micrographs confirmed that biogenic iron oxides dominate in the sample volume (Fig. 1a). The detailed morphological analysis shows that the biogenic structures represent a mixture of short and long hollow microtubules of almost straight shape with the following parameters: average outer and inner diameters of 1.6 and $0.9 \mu \mathrm{m}$, respectively (i.e., with the wall thickness approximately of $0.35 \mu \mathrm{m}$ ); the length range from 7 to $25 \mu \mathrm{m}$ (probably being fragments of longer and brittle microtubules). Chemically, the 

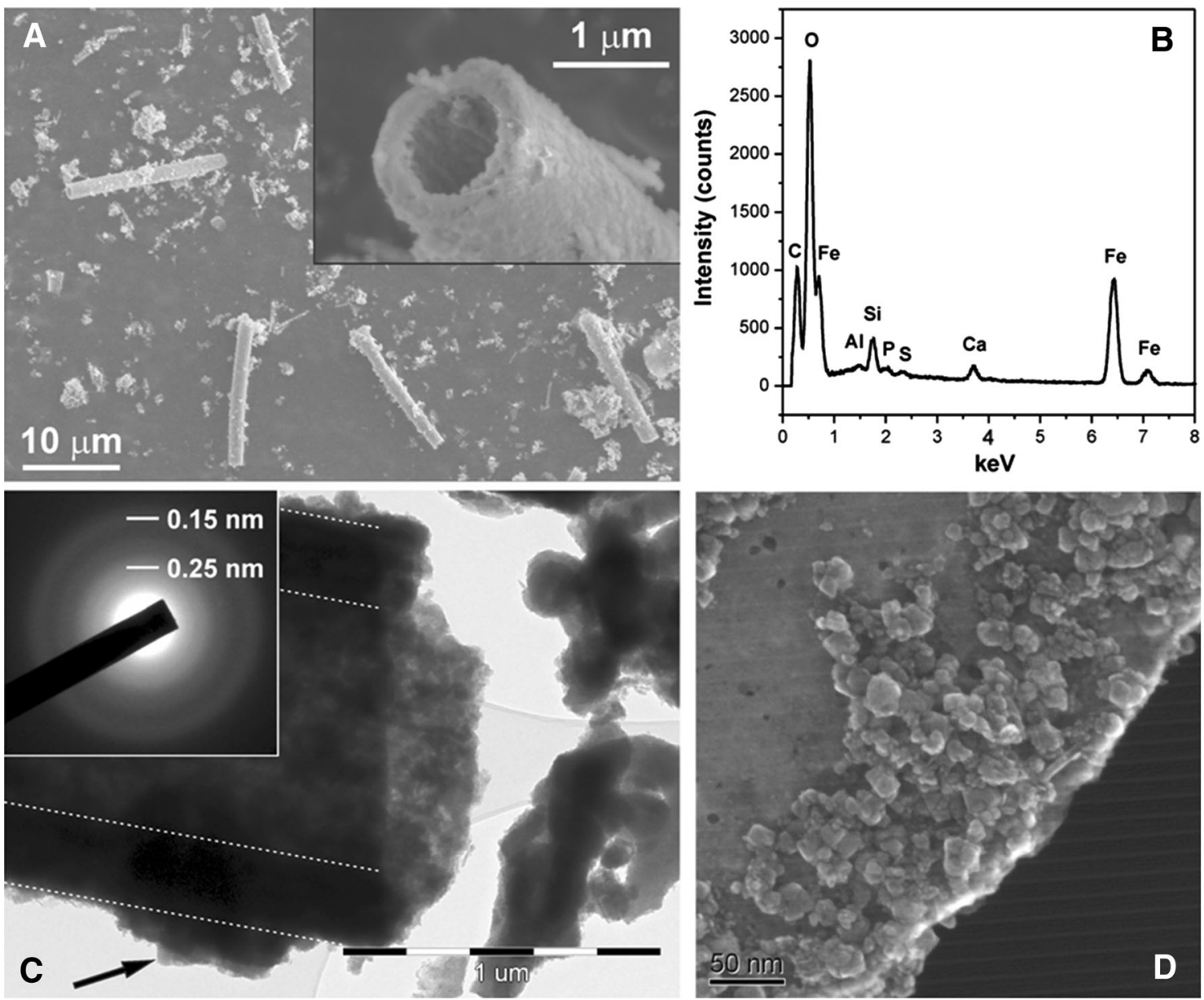

Fig. 1 Representative electron micrographs of biogenic iron oxides. a-SEM image shoving morphology of hollow microtubules formed by Leptothrix ochracea. b-Energy-dispersive X-ray spectrum collected from hollow microtubules showed in part a. c-TEM image

microtubules are composed mainly of $\mathrm{Fe}$ and $\mathrm{O}$ with minor amounts of $\mathrm{Si}, \mathrm{Al}$ and $\mathrm{Ca}$ (c.f., EDX spectrum in Fig. 1b). Crystalline phases, on the other hand, are usually between 1 and $100 \mu \mathrm{m}$ in size and their detrital origin is demonstrated by their angular morphology (Fig. 1a). From TEM images it is clear, that the microtubules are constructed by isometric nanoparticles with particle-size well below $100 \mathrm{~nm}$ (Fig. 1c) aggregated into larger structures. Using the STEM mode, it was possible to directly identify the maghemite particles (diameter typically between 10 and $15 \mathrm{~nm}$ ) on the surface of biogenic iron oxides and all crystalline components of sediment magnetically modified by magnetic fluid (see Fig. 1d). The active surface area of the bulk, magnetically-modified sample used further as magnetic sorbent is $148 \mathrm{~m}^{2} \mathrm{~g}^{-1}$.

The detailed phase analysis of the sample was derived from the combination of WDXRF, XRD, SAED, Mössbauer spectroscopy and magnetic measurements. The observed chemical composition of bulk unmodified sample showing the edge of hollow microtubules (unmodified sample; SAED is shown in inset; walls of the microtubules are highlighted); dmaghemite nanoparticles on the surface of the sediment modified with magnetic fluid

is given in Table 1 . The elements like $\mathrm{Si}, \mathrm{Al}, \mathrm{Mg}, \mathrm{Ca}, \mathrm{K}, \mathrm{Na}$ and $\mathrm{Ti}$ are typically related to the detrital minerals of sediment (quartz, phyllosilicates, etc.; see below), whereas prevailing $\mathrm{Fe}$, together with $\mathrm{P}, \mathrm{Mn}$ and partially also $\mathrm{Si}$ and $\mathrm{Ca}$ could be related to biogenic iron oxides (Hashimoto et al. 2007 and references therein). In the XRD pattern of the magnetically-modified solid sample, well crystalline phases of detrital origin dominate: quartz- $\mathrm{SiO}_{2}$, kaolinite- $-\mathrm{Al}_{2} \mathrm{Si}_{2} \mathrm{O}_{5}(\mathrm{OH})_{4}, \quad$ muscovite/illite- $\mathrm{KAl}_{2}\left(\mathrm{Si}_{3} \mathrm{Al}\right) \mathrm{O}_{10}$ $(\mathrm{OH})_{2}$ and feldspars-(Na,K) $\mathrm{AlSi}_{3} \mathrm{O}_{8}$ (Fig. 2). The dominant biogenic iron oxides itself are X-ray amorphous (compare with our previous paper (Hashimoto et al. 2007)); therefore, there is no clear evidence about their characteristics in the XRD pattern (Fig. 2). The only diffraction peak corresponding to iron oxides observed in the XRD pattern is at $\sim 41.5^{\circ} 2 \theta$ - the 212 diffraction of maghemite $\left(\gamma-\mathrm{Fe}_{2} \mathrm{O}_{3}\right)$ added into the sample during magnetic modification.

In order to gain insight into the character of the X-ray amorphous biogenic iron oxides we employed ${ }^{57} \mathrm{Fe}$ 
Table 1 Chemical composition of unmodified sediment consisting of biogenic iron oxides and minerals of detrital origin

\begin{tabular}{|c|c|}
\hline \multicolumn{2}{|l|}{ (wt\%) } \\
\hline $\mathrm{SiO}_{2}$ & 21.03 \\
\hline $\mathrm{Al}_{2} \mathrm{O}_{3}$ & 8.421 \\
\hline $\mathrm{Fe}_{2} \mathrm{O}_{3}$ & 44.98 \\
\hline $\mathrm{MgO}$ & 0.298 \\
\hline $\mathrm{CaO}$ & 2.491 \\
\hline $\mathrm{K}_{2} \mathrm{O}$ & 1.07 \\
\hline $\mathrm{Na}_{2} \mathrm{O}$ & 0.101 \\
\hline $\mathrm{TiO}_{2}$ & 0.527 \\
\hline $\mathrm{P}_{2} \mathrm{O}_{5}$ & 0.429 \\
\hline $\mathrm{MnO}$ & 0.167 \\
\hline $\mathrm{Tb}_{4} \mathrm{O}_{7}$ & 0.0226 \\
\hline $\mathrm{Cl}$ & 0.024 \\
\hline LOI & 19.90 \\
\hline $\mathrm{SO}_{3}^{\mathrm{a}}$ & 0.255 \\
\hline SUM & 99.46 \\
\hline \multicolumn{2}{|l|}{ (ppm) } \\
\hline $\mathrm{Sc}$ & 6 \\
\hline $\mathrm{V}$ & 52 \\
\hline $\mathrm{Cr}$ & 37 \\
\hline $\mathrm{Ni}$ & 26 \\
\hline $\mathrm{Cu}$ & 20 \\
\hline $\mathrm{Zn}$ & 511 \\
\hline $\mathrm{Ga}$ & 40 \\
\hline As & 41 \\
\hline $\mathrm{Rb}$ & 70 \\
\hline $\mathrm{Sr}$ & 90 \\
\hline $\mathrm{Y}$ & 42 \\
\hline $\mathrm{Zr}$ & 591 \\
\hline $\mathrm{Nb}$ & 15 \\
\hline $\mathrm{Ba}$ & 907 \\
\hline $\mathrm{La}$ & 141 \\
\hline $\mathrm{Ce}$ & 93 \\
\hline $\mathrm{Pb}$ & 29 \\
\hline $\mathrm{Th}$ & 19 \\
\hline $\mathrm{U}$ & 12 \\
\hline
\end{tabular}

${ }^{a}$ Included in LOI (Loss on ignition)

Mössbauer spectroscopy. It showed that all the iron atoms are octahedrally-coordinated in high-spin $\mathrm{Fe}^{3+}$ form; all of them are present in superparamagnetic phase at room temperature (one hyperfine doublet with isomer shift $\delta=0.34 \mathrm{~mm} \mathrm{~s}^{-1}$; quadruple splitting $=0.77 \mathrm{~mm} \mathrm{~s}^{-1}$, see Fig. 3; Table 2). At low temperature (5 K), the iron-bearing phase(s) are below a blocking temperature of magnetic ordering with low-temperature hyperfine parameters of sextet: $\delta \approx 0.44 \mathrm{~mm} \mathrm{~s}^{-1}$; quadruple shift $-0.05 \mathrm{~mm} \mathrm{~s}^{-1}$; hyperfine magnetic field $B_{\mathrm{hf}}=46.9 \mathrm{~T}$ (Fig. 3; Table 2). The broad width of spectral lines, as well as distribution of

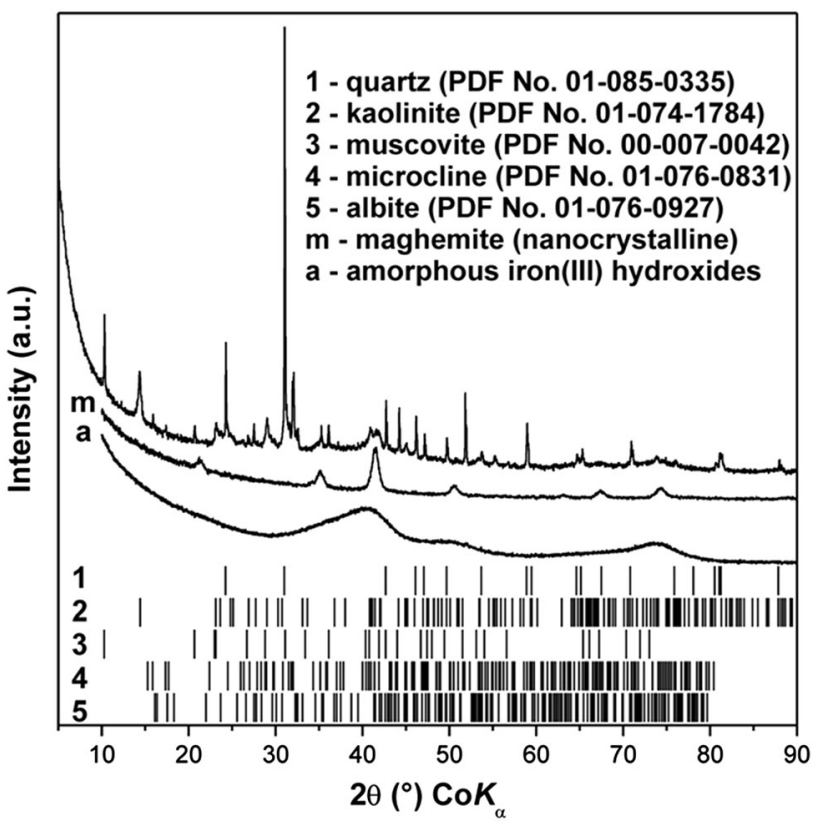

Fig. 2 Representative X-ray powder diffraction pattern of the studied magnetically modified sample of ochreous sediment containing biogenic iron oxides. The XRD patterns of nanocrystalline maghemite (marked as " $m$ "; particle size $\sim 12 \mathrm{~nm}$ ) and amorphous iron(III) hydroxides $(a)$ are given for comparison (unpublished data of authors)

hyperfine parameters (see Fig. 3) does not allow distinction of spectral components from amorphous biogenic iron oxides and nanocrystalline maghemite (superparamagnetic at RT with hyperfine parameters comparable to those in Table 2 for biogenic iron oxides) added into the sample during magnetic modification. The structure of biogenic iron oxide was further studied in detail using electron diffraction on selected sheaths (see inset in Fig. 1c). The SAED results clearly revealed two broad diffraction maxima corresponding to 0.15 and $0.25 \mathrm{~nm}$, confirming that the structure of biogenic iron oxides is similar to that of 2-line ferrihydrite (compare with our previous papers (Filip et al. 2007; Hashimoto et al. 2007)). It is in a full accordance with hyperfine parameters of Mössbauer spectra being identical to poorly-crystalline hydrous ferric oxide (i.e., 2-line ferrihydrite (Filip et al. 2007)). This is further supported by the fact that the studied biogenic iron oxides originated in aqueous environment; moreover, LOI indicate that the biogenic iron oxides are significantly hydrated (Table 1).

To better understand the structure and possibilities of magnetic separation of magnetically-modified biogenic iron oxides, we performed the detailed magnetic characterization exploiting SQUID magnetization measurements. As discussed above the studied sample is composed of maghemite, ferrihydrite nanoparticles, and other crystalline phases. Thus, the sample's magnetic response reflects the magnetic behavior of individual present phases that may change upon 

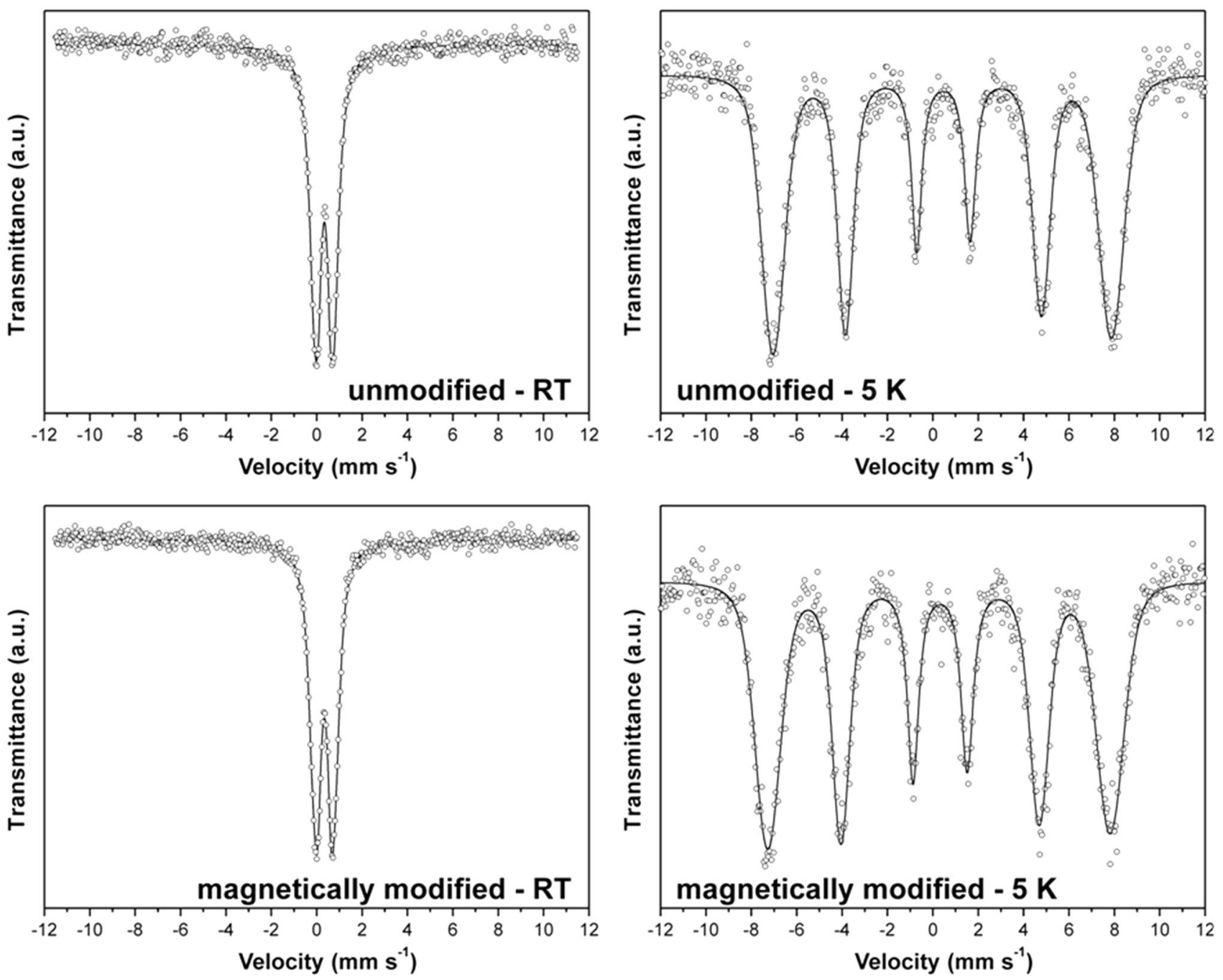

Fig. 3 Room- and low-temperature (5 K) Mössbauer spectra of studied solid samples. See Table 2 for more details

Table 2 Room-temperature (RT) and low-temperature (5 K) Mössbauer hyperfine parameters of both unmodified and magnetically modified samples of biogenic iron oxides, where $\delta$ is the isomer shift, $\Delta E_{\mathrm{Q}}$ is the quadrupole splitting (shift), $B_{\mathrm{hf}}$ is hyperfine magnetic field, and $\Gamma$ is line width

\begin{tabular}{lllcll}
\hline Sample & Temperature & $\delta \pm 0.01\left(\mathrm{~mm} \mathrm{~s}^{-1}\right)$ & $\Delta E_{\mathrm{Q}} \pm 0.01\left(\mathrm{~mm} \mathrm{~s}^{-1}\right)$ & $B_{\mathrm{hf}} \pm 0.3(\mathrm{~T})$ & $\Gamma \pm 0.01\left(\mathrm{~mm} \mathrm{~s}^{-1}\right)$ \\
\hline Unmodified & RT & 0.34 & 0.77 & - & 0.53 \\
Unmodified & $5 \mathrm{~K}$ & 0.44 & -0.05 & 46.3 & $0.51^{\mathrm{a}}$ \\
Mag. modified & RT & 0.34 & 0.77 & - & 0.54 \\
Mag. modified & $5 \mathrm{~K}$ & 0.44 & -0.05 & 46.9 & $0.48^{\mathrm{a}}$ \\
\hline
\end{tabular}

${ }^{a}$ Fitted as distribution of hyperfine parameters

warming and/or cooling the sample. At $5 \mathrm{~K}$, the magnetization versus applied magnetic field curve exhibits a hysteresis indicating predominantly a magnetically ordered state of the studied sample (Fig. 4). The value of coercivity is rather low and falls within the range expected for iron oxide nanoparticles. However, the sample does not reach saturation at the highest applied magnetic field of $7 \mathrm{~T}$. This may be a result of either the finite-size and surface effects driving the magnetic behavior of magnetic nanoparticles (maghemite and ferrihydrite) in the blocked state and/or paramagnetic response of other crystalline phases. As the temperature increases, magnetic nanoparticles gradually enter a superparamagnetic state at temperatures depending primarily on a size of an individual nanoparticle. At $300 \mathrm{~K}$, all magnetic 


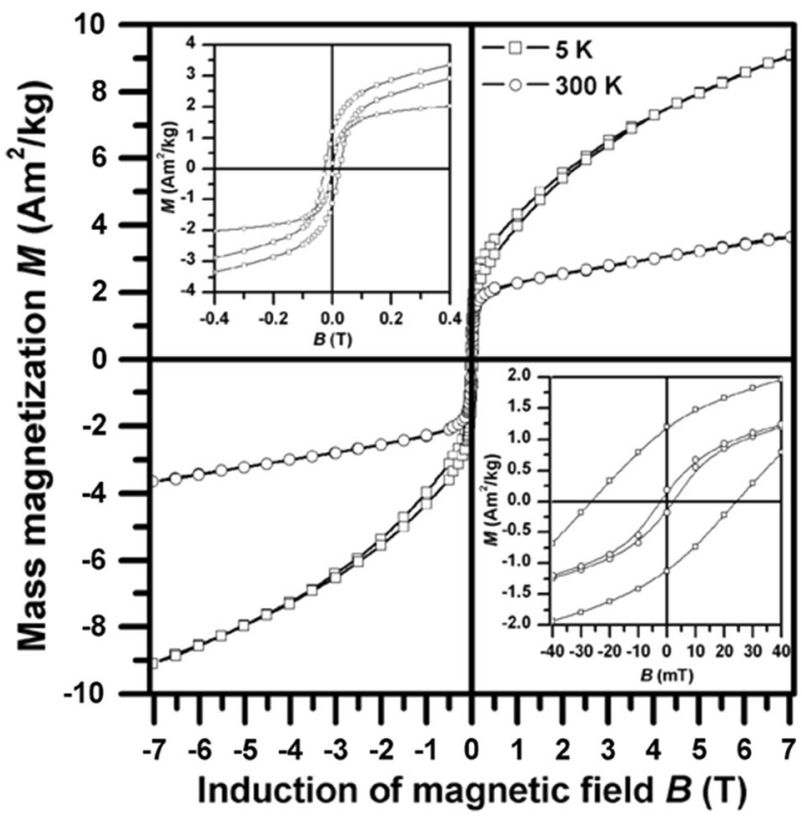

Fig. 4 Hysteresis loop of the studied sample, measured at a temperature of 5 and $300 \mathrm{~K}$

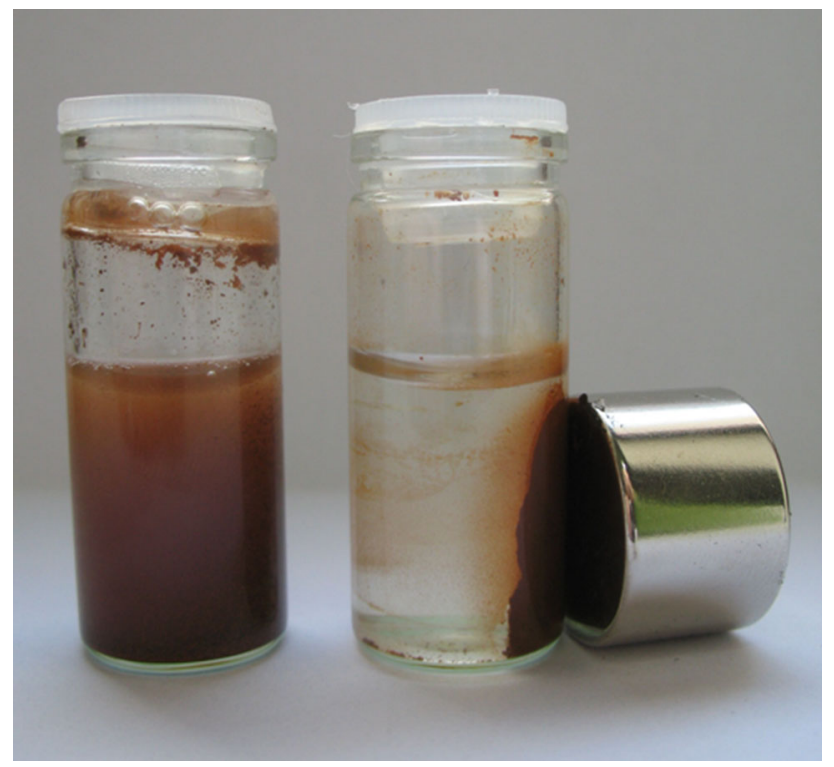

Fig. 5 Demonstration of magnetic separation of magnetically modified biogenic iron oxides

nanoparticles behave in a superparamagnetic manner with respect to the characteristic measuring time of the SQUID technique $(\sim 10 \mathrm{~s})$. This is documented by a significant reduction in the area of the room-temperature hysteresis loop compared to that observed at $5 \mathrm{~K}$. However, the nonzero value of the coercivity and remanent magnetization (Fig. 4) implies that there exist some phase that is in a magnetically ordered state, most probably of ferromagnetic and/or ferrimagnetic origin. As the room-temperature Mössbauer spectrum displays only a doublet, this indicates that the hysteresis character of the room-temperature magnetization versus applied magnetic field curve originates from non-iron bearing phase(s). Again, at higher applied magnetic fields, the profile of the sample's hysteresis loop is governed by phases exhibiting a paramagnetic behavior. If we subtract these paramagnetic contributions, we get a saturation magnetization of $\sim 2 \mathrm{Am}^{2} \mathrm{~kg}^{-1}$ achievable at relatively low applied magnetic fields $(\sim 1 \mathrm{~T})$. Although the value of saturation magnetization is low, the magnetically modified sample of biogenic iron oxides exhibits a sufficient magnetic response at low applied magnetic fields and can be easily and effectively separated from an aqueous medium employing a simple magnet (see Fig. 5). Therefore, magnetically modified biogenic iron oxides of L. ochracea are well applicable as a magnetic sorbent with a large surface area.

To conclude the characterizations of magnetically modified natural sediment, we should mention that the ironrich sorbents (i.e., those containing iron oxides) intended for removal of various pollutants in innovative filtration techniques are typically based on iron oxide coated sand (Hanna 2007; Ko et al. 2007). Therefore, the presence of oxides and silicate minerals in the present sample of natural sediment containing biogenic iron oxides is not critical and it could be further evaluated as possible industrial adsorbent (see below). Moreover, it should be emphasized that different kinds of iron waste are routinely used as suitable adsorbents for various kinds of pollutants (Tien et al. 2009). Therefore, the magnetic modification of the natural sediment containing biogenic iron oxides nanoparticles (this study) could enable its exploitation into the form of the cheap and efficient magnetic iron-rich adsorbent.

Adsorption of organic xenobiotics on magnetically modified biogenic iron oxides

Biosorption of both inorganic and organic xenobiotics using a variety of biological materials represents emerging possibility for the reduction of environmental pollution. Enormous amount of biological materials has been tested in many laboratories all over the world (Srinivasan and Viraraghavan 2010; Volesky and Holan 1995). In most cases biosorbents are based on plant materials, microbial biomass or different types of polysaccharides. However, relatively low attention is being paid to "inorganic biosorbents" such as biogenic iron oxides.

In order to improve manipulation with biosorbents, their magnetic derivatives can be prepared and used (Safarik et al. 2011a). Magnetically modified sample of biogenic iron oxides can be easily separated by simple magnets (see Fig. 5). This material was used as an sorbent to study the binding of seven water-soluble dyes belonging to different 


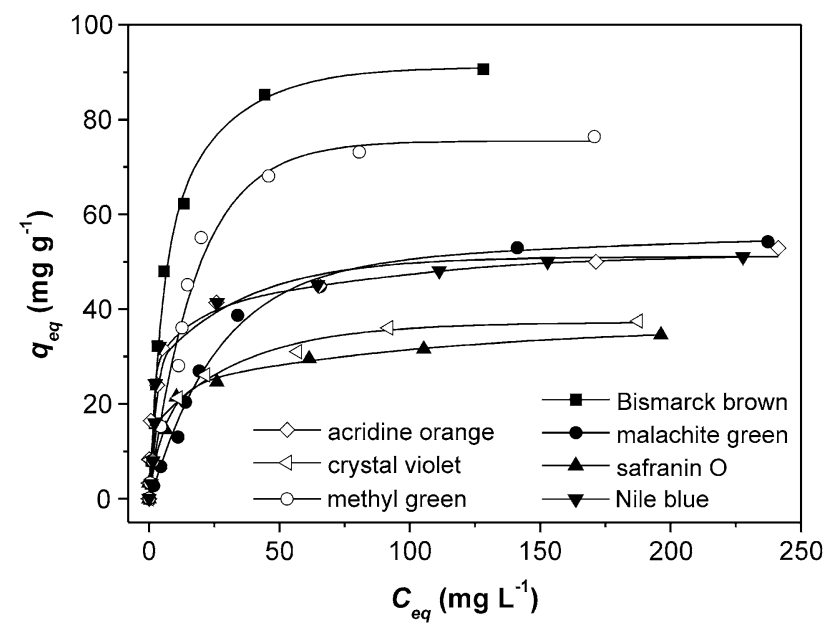

Fig. 6 Equilibrium adsorption isotherms of the tested dyes using magnetically modified biogenic iron oxides as sorbent. $C_{\mathrm{eq}}$ equilibrium liquid-phase concentration of the unadsorbed (free) dye $\left(\mathrm{mg} \mathrm{L}^{-1}\right) ; q_{\text {eq }}$ equilibrium solid-phase concentration of the adsorbed dye $\left(\mathrm{mg} \mathrm{g}^{-1}\right)$

dye classes. The tested dyes comprehended crystal violet, methyl green and malachite green (triphenylmethane group), Bismarck brown $\mathrm{Y}$ (azodyes group), acridine orange (acridine group), Nile blue A (oxazin group) and safranin $\mathrm{O}$ (safranin group); chemical structures of the dyes are shown in Electronic Supplementary Material, Table S1. Commercially available dyes were used during the experiments; they were dissolved in distilled water without buffering the solution. The $\mathrm{pH}$ values of the dyes solutions ranged between 4.0 and 5.7.

The adsorption of the tested dyes reached equilibrium in approximately 30-120 min (see Electronic Supplementary Material, Fig. S2). In order to achieve equilibrium during the adsorption process, incubation time of $3 \mathrm{~h}$ was used for all adsorption experiments.

The equilibrium adsorption isotherms for the unbuffered aqueous solutions of the tested dyes are shown in Fig. 5. These isotherms represent distribution of dyes between the aqueous and solid phases as the dye concentration increases. Langmuir and Freundlich isotherm equations are usually used for experimental data analysis in order to study the adsorption of target analytes from water solutions.

The Langmuir model is valid for monolayer adsorption onto a surface with a finite number of identical sites. The well known expression for the Langmuir model is given by

$q_{\mathrm{eq}}=\frac{Q_{\mathrm{max}} b C_{\mathrm{eq}}}{1+b C_{\mathrm{eq}}}$

where $q_{\mathrm{eq}}$ (expressed in $\mathrm{mg} \mathrm{g}^{-1}$ or $\mathrm{mg} \mathrm{mL}^{-1}$ ) is the amount of the adsorbed dye per unit mass or sedimented volume of magnetically modified biomass and $C_{\mathrm{eq}}$ (expressed in $\mathrm{m} \mathrm{L} \mathrm{L}^{-1}$ ) is the unadsorbed dye concentration
Table 3 Isotherms used for the description of dyes adsorption on magnetically modified biogenic iron oxides and calculated adsorption $\left(K_{\mathrm{F}}, Q_{\mathrm{max}}, b, n\right)$ coefficients. $Q_{\max }$ is expressed as $\mathrm{mg}$ of adsorbed dye per one $g$ of magnetic sorbent

\begin{tabular}{lll}
\hline Dyes & $\begin{array}{l}\text { Freundlich isotherm } \\
q_{\mathrm{eq}}=K_{\mathrm{F}} C_{\mathrm{eq}}^{n}\end{array}$ & $\begin{array}{l}\text { Langmuir isotherm } \\
q_{\mathrm{eq}}=\frac{Q_{\max } b C_{\mathrm{eq}}}{1+b C_{\mathrm{eq}}}\end{array}$ \\
\hline Acridine orange & $K_{\mathrm{F}}=21.6$ & $Q_{\max }=49.3$ \\
& $n=0.168$ & $b=0.364$ \\
Bismarck brown & $K_{\mathrm{F}}=20.5$ & $Q_{\max }=97.8$ \\
& $n=0.332$ & $b=0.133$ \\
Crystal violet & $K_{\mathrm{F}}=12.4$ & $Q_{\max }=36.7$ \\
Malachite green & $n=0.222$ & $b=0.155$ \\
& $K_{\mathrm{F}}=7.80$ & $Q_{\max }=62.9$ \\
Methyl green & $n=0.377$ & $b=0.036$ \\
Nile blue A & $K_{\mathrm{F}}=15.2$ & $Q_{\max }=87.6$ \\
& $n=0.342$ & $b=0.061$ \\
Safranin O & $K_{\mathrm{F}}=15.7$ & $Q_{\max }=50.1$ \\
& $n=0.235$ & $b=0.259$ \\
& $K_{\mathrm{F}}=10.2$ & $Q_{\max }=34.3$ \\
& $n=0.244$ & $b=0.125$ \\
\hline
\end{tabular}

in solution at equilibrium. $Q_{\max }$ is the maximum amount of the dye per unit mass of adsorbent to form a complete monolayer on the surface bound at high dye concentration and $b$ is a constant related to the affinity of the binding sites (expressed in $\mathrm{L} \mathrm{mg}^{-1}$ ) (Fig. 6) (Safarik et al. 2007).

The empirical Freundlich equation based on the sorption onto a heterogeneous surface is given by

$q_{\mathrm{eq}}=K_{\mathrm{F}} C_{\mathrm{eq}}^{n}$

where $K_{\mathrm{F}}$ and $n$ are the Freundlich constants characteristic of the system. $K_{\mathrm{F}}$ and $n$ are indicators of adsorption capacity and adsorption intensity, respectively.

Non-linear regression calculation is currently the preferred way to calculate the constants $\left(Q_{\max }, b, n, K_{\mathrm{F}}\right)$. The results are presented in Table 3. As can be seen, the highest $Q_{\max }$ was found for Bismarck brown $\left(97.8 \mathrm{mg} \mathrm{g}^{-1}\right)$, while the lowest $Q_{\max }$ value was obtained for safranin $\mathrm{O}$ $\left(34.3 \mathrm{mg} \mathrm{g}^{-1}\right)$. The values of regression coefficients indicate that Langmuir isotherm can be used for the description of adsorption of all the tested dyes. In some cases, however, Freundlich isotherm can be used, as well (e.g., for crystal violet).

The maximum adsorption capacity values $Q_{\max }$ obtained for magnetically modified sample of biogenic iron oxides are in most cases at least comparable with literature data for other similar iron-rich sorbents (both in non-magnetic and magnetic forms). Recently goethite and magnetite have been used as adsorbents for fluorescein, Eriochrome blue black R and alizarin; maximum adsorption capacities for magnetite $\left(3.8,15.3\right.$ and $65.8 \mathrm{mg} \mathrm{g}^{-1}$, resp.) and goethite 
Table 4 Maximum adsorption capacities $Q_{\max }\left(\mathrm{mg} \mathrm{g}^{-1}\right)$ of magnetically modified biosorbents for the tested dyes

\begin{tabular}{|c|c|c|c|c|c|c|c|}
\hline & $\begin{array}{l}\text { Acridine } \\
\text { orange }\end{array}$ & $\begin{array}{l}\text { Bismarck } \\
\text { brown Y }\end{array}$ & $\begin{array}{l}\text { Crystal } \\
\text { violet }\end{array}$ & $\begin{array}{l}\text { Malachite } \\
\text { green }\end{array}$ & $\begin{array}{l}\text { Methyl } \\
\text { green }\end{array}$ & $\begin{array}{l}\text { Nile } \\
\text { blue A }\end{array}$ & $\begin{array}{l}\text { Safranin } \\
\text { O }\end{array}$ \\
\hline Saccharomyces cerevisiae (Safarik et al. 2002) & 82.2 & & 85.9 & & & & 90.3 \\
\hline $\begin{array}{l}\text { Saccharomyces cerevisiae subsp. uvarum } \\
\text { (Safarikova et al. 2005) }\end{array}$ & & & 41.7 & & & & 46.6 \\
\hline Kluyveromyces fragilis (Safarik et al. 2007) & 62.2 & 75.7 & 42.9 & & & & 138.2 \\
\hline Chlorella vulgaris (Safarikova et al. 2008) & & 201.9 & 42.9 & & & & 115.7 \\
\hline Spruce sawdust (Safarik et al. 2005) & 24.1 & 52.1 & 52.4 & & & & 25.0 \\
\hline Spent grain (Safarik et al. 2011b) & & 72.4 & 40.2 & & & 64.1 & \\
\hline Spent coffee grounds (Safarik et al. 2012) & 73.4 & 69.2 & 68.1 & 43.0 & & & 59.0 \\
\hline Peanut husk (Safarik and Safarikova 2010b) & 71.4 & 95.3 & 80.9 & & & & 86.1 \\
\hline Biogenic iron oxides (this paper) & 49.3 & 97.8 & 36.7 & 62.9 & 87.6 & 50.1 & 34.3 \\
\hline
\end{tabular}

(33.2, 27.7 and $370 \mathrm{mg} \mathrm{g}^{-1}$, resp.) confirm this statement (Pirillo et al. 2009). The comparison of magnetic biogenic iron oxides (a typical representative of "inorganic biosorbents") with recently developed magnetically responsive biosorbents is shown in Table 4; again, all the magnetic biosorbents are comparable from the point of view of maximum adsorption capacities. Preliminary experiments have shown that magnetic modification of biogenic iron oxides had no substantial effect on the maximum adsorption capacities for the tested dyes.

Another comparison is shown in Table S2 in Electronic Supplementary Material; adsorption of malachite green on various low-cost biosorbents and magnetic biogenic iron oxides is compared. Malachite green is an illegal fish drug used in the fish farming industry as a fungicide, ectoparasiticide and disinfectant; this dye is cytotoxic to mammalian cells and that's why its use has been banned in aquacultures intended to produce fish for human consumption (Safarik and Safarikova 2002a). Removal of this dye from water resources by adsorption is one of the intensively studied problems. The commonly used adsorbent, activated carbon, has good capacity for pollutants removal; however, it is rather expensive due to the high price of treatment and difficult regeneration. Thus, lowcost adsorbents requiring minimum pretreatment steps are necessary. Magnetic biogenic iron oxides exhibit good adsorption properties for this dye and should be considered as a promising adsorbent.

It should be taken into account that adsorption process can be strongly influenced by the reaction conditions, such as $\mathrm{pH}$, ionic strength, presence of accompanying compounds etc. The increase of $\mathrm{pH}$ has usually increased the values of maximum adsorption capacities of the tested dyes (data not shown). Iron oxides below their point of zero charge (PZC) are protonated which leads to the formation of $\equiv \mathrm{Fe}-\mathrm{OH}_{2}{ }^{+}$moieties, while deprotonation occurring above the $\mathrm{PZC}$ gives rise to $\equiv \mathrm{Fe}-\mathrm{O}^{-}$surface moieties, which affect the electrostatic attachments of the organic compounds on the magnetic iron oxide particles (Qiao et al. 2009).

In addition to electrostatic interactions several other general mechanisms can contribute to the adsorption of organic compounds onto the studied iron oxides-containing magnetic adsorbent. Such mechanisms can involve ligand exchange-surface complexation, hydrophobic interaction, hydrogen bonding, and cation bridging $(\mathrm{Gu}$ et al. 1994).

To conclude, maximum adsorption capacities of the developed material reached values up to almost $100 \mathrm{mg}$ of adsorbed dyes per $1 \mathrm{~g}$ of magnetic biosorbent which is fully comparable with other described non-magnetic biosorbents used for the same purpose (Srinivasan and Viraraghavan 2010). Magnetic modification enabling the simple magnetic separation makes the described biosorbent superior to other non-magnetic materials. It should be taken into consideration, however, that the adsorption properties of this material are strongly dependent on the dye type and conditions during the adsorption process.

\section{Conclusion}

Magnetically responsive derivate of biogenic iron oxides has been prepared by ferrofluid modification of natural ochreous sediment. Both unmodified and magnetically modified biogenic iron oxides were characterized in detail. Biogenic iron oxides exhibited high adsorption capacity for selected organic xenobiotics (dyes); their magnetic modification has increased their potential applicability in large scale processes.

Acknowledgments The authors thank to Klara Safarova for electron microscope characterization of the studied samples and Jiri Pechousek for surface area measurement. This work was supported by 
the research Projects LH11111 and LH12190 (Ministry of Education of the Czech Republic), 13-13709S (Grant Agency of the Czech Republic), Grant from the Technology Agency of the Czech Republic "Competence Centres" (Project TE01020218), by the Operational Program Research and Development for Innovations-European Social Fund (CZ.1.05/2.1.00/03.0058) and by the Joint Research Project FY2011 in the JSPS Bilateral Programs, supported by Ministry of Education, Culture, Sports, Science and Technology of Japan. This study was also supported by JST, CREST. Ivo Safarik thanks the Japanese Society for the Promotion of Science for the financial support of his study stay in Japan in 2010.

\section{References}

Bazylinski DA, Frankel RB, Konhauser KO (2007) Modes of biomineralization of magnetite by microbes. Geomicrobiol $\mathrm{J}$ 24:465-475

Bolto BA (1996) Magnetic particle technology: desalination and water reuse applications. Desalination 106:137-143

Chitrakar R, Tezuka S, Sonoda A, Sakane K, Ooi K, Hirotsu T (2006) Phosphate adsorption on synthetic goethite and akaganeite. J Colloid Interface Sci 298:602-608

Emerson E, Fleming EJ, McBeth JM (2010) Iron-oxidizing bacteria: an environmental and genomic perspective. Annu Rev Microbiol 64:561-583

Filip J, Zboril R, Schneeweiss O, Zeman J, Cernik M, Kvapil P, Otyepka M (2007) Environmental applications of chemically pure natural ferrihydrite. Environ Sci Technol 41:4367-4374

Ghiorse WC (1984) Biology of iron- and manganese-depositing bacteria. Annu Rev Microbiol 38:515-550

Gu B, Schmitt J, Chen Z, Llang L, McCarthy JF (1994) Adsorption and desorption of natural organic matter on iron oxide: mechanisms and models. Environ Sci Technol 28:38-48

Hanna K (2007) Adsorption of aromatic carboxylate compounds on the surface of synthesized iron oxide-coated sands. Appl Geochem 22:2045-2053

Hartley W, Lepp NW (2008) Remediation of arsenic contaminated soils by iron-oxide application, evaluated in terms of plant productivity, arsenic and phytotoxic metal uptake. Sci Total Environ 390:35-44

Hashimoto H, Yokoyama S, Asaoka H, Kusano Y, Ikeda Y, Seno M, Takada J, Fujii T, Nakanishi M, Murakami R (2007) Characteristics of hollow microtubes consisting of amorphous iron oxide nanoparticles produced by iron oxidizing bacteria, Leptothrix ochracea. J Magn Magn Mater 310:2405-2407

James RE, Ferris FG (2004) Evidence for microbial-mediated iron oxidation at a neutrophilic groundwater spring. Chem Geol 212:301-311

Jeong Y, Fan M, Singh S, Chuang C-L, Saha B, Hans van Leeuwen J (2007) Evaluation of iron oxide and aluminum oxide as potential arsenic(V) adsorbents. Chem Eng Process 46:1030-1039

Kang S-K, Choo K-H, Lim K-H (2003) Use of iron oxide particles as adsorbents to enhance phosphorus removal from secondary wastewater effluent. Sep Sci Technol 38:3853-3874

Katsoyiannis IA, Zouboulis AI (2004) Application of biological processes for the removal of arsenic from groundwaters. Water Res 38:17-26

Kiwada H, Sato J, Yamada S, Kato Y (1986) Feasibility of magnetic liposomes as a targeting device for drugs. Chem Pharm Bull 34:4253-4258

Ko L, Davis AP, Kim JY, Kim KW (2007) Arsenic removal by a colloidal iron oxide coated sand. J Environ Eng 133:891-898

Massart R (1981) Preparation of aqueous magnetic liquids in alkaline and acidic media. IEEE Trans Magn 17:1247-1248
Mayer TD, Jarrell WM (2000) Phosphorus sorption during iron(II) oxidation in the presence of dissolved silica. Water Res 34:3949-3956

Pirillo S, Pedroni V, Rueda E, Ferreira ML (2009) Elimination of dyes from aqueous solutions using iron oxides and chitosan as adsorbents. A comparative study. Quim Nova 32:1239-1244

Pokhrel D, Viraraghavan T (2009) Biological filtration for removal of arsenic from drinking water. J Environ Manag 90:1956-1961

Qiao R, Yang C, Gao M (2009) Superparamagnetic iron oxide nanoparticles: from preparations to in vivo MRI applications. J Mater Chem 19:6274-6293

Rentz JA, Turner IP, Ullman JL (2009) Removal of phosphorus from solution using biogenic iron oxides. Water Res 43:2029-2035

Sabbatini P, Rossi F, Thern G, Marajofsky A, de Cortalezzi MMF (2009) Iron oxide adsorbers for arsenic removal: a low cost treatment for rural areas and mobile applications. Desalination 248:184-192

Safarik I, Safarikova M (2002a) Detection of low concentrations of malachite green and crystal violet in water. Water Res 36:196-200

Safarik I, Safarikova M (2002b) Magnetic nanoparticles and biosciences. Mon Chem 133:737-759

Safarik I, Safarikova M (2009) Magnetic nano- and microparticles in biotechnology. Chem Pap 63:497-505

Safarik I, Safarikova M (2010a) Magnetically responsive (nano)composites as perspective materials for environmental technology applications. ENT Mag (January-February) 85-90

Safarik I, Safarikova M (2010b) Magnetic fluid modified peanut husks as an adsorbent for organic dyes removal. Phys Procedia 9:274-278

Safarik I, Ptackova L, Safarikova M (2002) Adsorption of dyes on magnetically labeled baker's yeast cells. Eur Cell Mater 3(Suppl. 2):52-55

Safarik I, Safarikova M, Weyda F, Mosiniewicz-Szablewska E, SlawskaWaniewska A (2005) Ferrofluid-modified plant-based materials as adsorbents for batch separation of selected biologically active compounds and xenobiotics. J Magn Magn Mater 293:371-376

Safarik I, Rego LFT, Borovska M, Mosiniewicz-Szablewska E, Weyda F, Safarikova M (2007) New magnetically responsive yeast-based biosorbent for the efficient removal of water-soluble dyes. Enzyme Microb Technol 40:1551-1556

Safarik I, Horska K, Safarikova M (2011a) Magnetically responsive biocomposites for inorganic and organic xenobiotics removal. In: Kotrba P, Mackova M, Macek T (eds) Microbial biosorption of metals. Springer, Berlin, pp 301-320

Safarik I, Horska K, Safarikova M (2011b) Magnetically modified spent grain for dye removal. J Cereal Sci 53:78-80

Safarik I, Horska K, Svobodova B, Safarikova M (2012) Magnetically modified spent coffee grounds for dyes removal. Eur Food Res Technol 234:345-350

Safarikova M, Safarik I (2001) The application of magnetic techniques in biosciences. Magn Electr Sep 10:223-252

Safarikova M, Ptackova L, Kibrikova I, Safarik I (2005) Biosorption of water-soluble dyes on magnetically modified Saccharomyces cerevisiae subsp. uvarum cells. Chemosphere 59:831-835

Safarikova M, Pona BMR, Mosiniewicz-Szablewska E, Weyda F, Safarik I (2008) Dye adsorption on magnetically modified Chlorella vulgaris cells. Fresenius Environ Bull 17:486-492

Srinivasan A, Viraraghavan T (2010) Decolorization of dye wastewaters by biosorbents: a review. J Environ Manag 91:1915-1929

Tien VN, Thi VTN, Tuan LP, Vigneswaran S, Huu HN, Kandasamy J, Hong KN, Duc TN (2009) Adsorption and removal of arsenic from water by iron ore mining waste. Water Sci Technol 60:2301-2308

Volesky B, Holan ZR (1995) Biosorption of heavy metals. Biotechnol Prog 11:235-250

Zak T, Jiraskova Y (2006) CONFIT: Mossbauer spectra fitting program. Surf Interface Anal 38:710-714 